\title{
Cavernomas of the central nervous system: clinical and neuroimaging manifestations in 47 patients
}

\author{
I Requena, M Arias, L López-Ibor, I Pereiro, A Barba, A Alonso, E Montón
}

\begin{abstract}
Forty seven cases of central nervous system cavernous angioma ( 21 males and 26 females) are described. The main clinical signs were epilepsy and brainstem syndromes. Digital subtraction intraarterial angiography, when used, failed to reveal cavernoma. CT detected many of the lesions, but the most successful supplementary diagnostic procedure was MRI which produces highly characteristic images of cavernous angioma. The diagnosis of cavernous angioma was confirmed in the 18 cases in which the tumour was removed surgically.
\end{abstract}

The four categories of vascular malformations of the CNS are, in descending order of incidence, arteriovenous malformation, cavernous angioma, venous angioma and telangiectasis. ${ }^{1}$ Since cavernous angiomas (cavernomas) are slow-flow vascular lesions, their angiographic appearance is avascular, and they are accordingly classed together with venous angioma, telangiectasis and thrombosed arteriovenous angioma as "cryptic" or "angiographically occult" CNS vascular malformations. ${ }^{2-7}$ Cavernomas consist of sinusoid vascular spaces with a single layer of endothelial cells separated from each other by connective tissue without intervening neural components. They have no connective capsule, but are usually well delimited by peripheral gliosis. Intrinsic thrombosis and haemorrhage frequently occur, as does calcification, which is probably secondary to the former events. Cholesterol and haemosiderin deposits may also be found. . $^{8-11}$

The incidence of cavernomas is not known precisely, different studies have reported them as accounting for $2-17 \%$ of $\mathrm{CNS}$ vascular malformations. ${ }^{12-15}$ In 1976 Voigt and Yasargil $^{16}$ reviewed 164 published cases, 100 of them based on necropsies. There are multiple and familial cavernomas. ${ }^{16-20}$ Cavernomas are often asymptomatic, and when symptoms are present they depend on the location and the size of the lesion. Cavernomas are usually located in the supratentorial compartment, preferably in the white matter, but have also been reported in intraventricular, pineal and dural locations and in the cavernous sinus, in Meckel's cave and the ponto-cerebellar angle. ${ }^{21-25}$ Clinical manifestations, the most important of which are epilepsy and focal neurological deficits, ${ }^{15}$ are due to compression, but cavernomas never give rise to ischaemic symptoms such as occur with high-flow vascular malformations. ${ }^{8}$ Except in the rare case of hypervascular cavernomas, ${ }^{26}$ cavernomas do not show up on angiograms, or at most give rise to nonspecific angiographic abnormalities. $^{2-7}$ CT and MRI, however, have both proved to be valuable diagnostic aids, the latter especially ${ }^{28}$ (the number of cavernomas diagnosed may be expected to increase rapidly in the near future). CT shows cavernomas as hyperdense or heterogeneous lesions (more rarely as hypodense ones), and a variable degree of enhancement after intravenous contrast injection is quite common, as is calcification. $^{27-30}$ Triple-dose injection with delayed detection has been used to improve sensitivity. ${ }^{31} 32$

In this article we describe and discuss the clinical, angiographic, CT and MRI signs of 47 patients with CNS cavernomas.

\section{Patients and methods}

We studied retrospectively 47 patients in a three year period (December 1986-November 1989) with various neurological manifestations, referred to our centre from all areas of our country. In all cases clinical histories were recorded and neurological examination performed by a neurologist. Digital subtraction intra-arterial angiography was carried out in 24 cases (double contrast dose injection and repeated radiology was not used). Cranial CT was performed in 45 patients before and after intravenous contrast injection; in no cases was a triple dose with delayed detection used. MRI was performed in all 47 patients using a Philips $0.5 \mathrm{~T}$ Gyroscan; 6-8 mm sagittal, axial and coronal sections were taken using spin-echo sequences with T1 (TR $500 \mathrm{~ms}$, TE $50 \mathrm{~ms}$ ) and T2 (TR 1500-2200 ms, TE1 $50 \mathrm{~ms}$, TE2 $100 \mathrm{~ms}$ ) weighted and without paramagnetic contrast; the number, location, size (maximum diameter) and signal characteristics of lesions was recorded in each case. Neuroimaging studies were carried out and evaluated by a neuroradiologist.

\section{Results}

Of the 47 patients studied, $26(55 \cdot 3 \%)$ were females and $21(44 \cdot 7 \%)$ males. Age at diagnosis was 39 years (range 5-79 years) in the whole patients group, 44.5 years in the female group (range 15-69 years) and 32.2 years in the male group (range 5-79 years). Clinical signs are listed in table 1 together with the number and percentage of cases in which each was observed.

None of the 24 angiograms showed the presence of a cavernoma. The abnormalities that did show up in angiograms were avas- 
Table 1 Clinical manifestations in 47 patients with cavernomas of CNS

\begin{tabular}{lcc}
\hline & Number & $\%$ \\
\hline Epilepsy & 16 & 34 \\
Brainstem syndromes & 14 & 30 \\
Focal hemispheric deficits & 5 & $10 \cdot 6$ \\
Subarachnoid haemorrhage & 1 & $2 \cdot 1$ \\
Cerebellar syndromes & 2 & $4 \cdot 3$ \\
Intracranial hypertension & 1 & $2 \cdot 1$ \\
Spastic paraparesis & 1 & $2 \cdot 1$ \\
Epilepsy and subarachnoid haemorrhage & 1 & $2 \cdot 1$ \\
Epilepsy and cerebellar syndromes & 1 & $2 \cdot 1$ \\
Incidental findings & 5 & 10.6 \\
\hline
\end{tabular}

cular masses associated with vascular displacement (in four patients), early venous drainage (two patients) and an abnormal surface venous system arrangement (in one patient).

CT allowed detection of lesions in 40 of the 45 patients with whom it was used. The images were hyperdense or heterogeneous in 35 cases and hypodense in 5. Nine lesions were calcified. One patient exhibited triventricular hydrocephalus with suspected intrinsic aqueductal stenosis, and another a parasagittal meningioma. Intravenous contrast injection achieved variable enhancement of lesions that were visible under CT without contrast.

MRI showed 56 cavernomas in the 47 patients studied, six of the patients proved to have multiple lesions. The T2-weighted images of the cavernomas showed well-defined lesions with a low peripheral signal due to haemosiderin and a heterogeneous central signal due to haemosiderin, calcium and blood in various states (flow, thrombosis, haemorrhage), while recently growing cavernomas (because of intralesional haemorrhage or thrombosis) occasionally produced images with a high-signal outer ring due to gliosis and/or oedema. The T1-weighted images

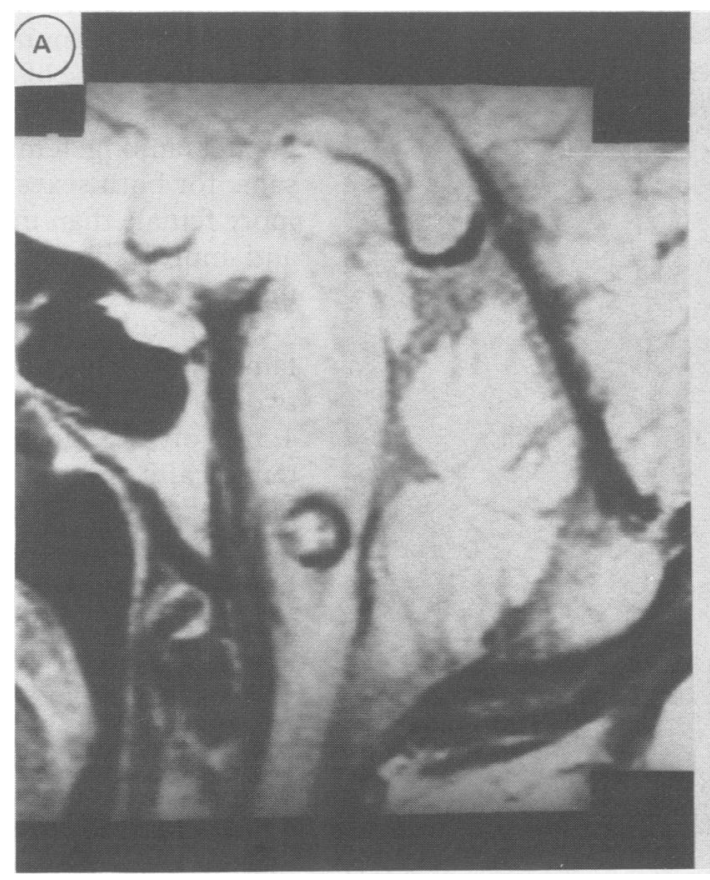

Table 2 MRI signal characteristics of cavernoma components

\begin{tabular}{ll}
\hline Component & T1 signal \\
\hline Blood: & T2 signal \\
Flow & \\
Fresh haemorrhage (haemoglobin) & $=$ \\
Haemorrhage $>48$ h (metaHb) & \\
Old haemorrhage (haemosiderin) & \\
Calcium & $=1$ \\
Gliosis & $=1$
\end{tabular}

: High signal; ( Low signal; =: Isosignal.

showed the haemosiderin peripheral low signal with a heterogeneous central signal, whilst peripheral oedema and gliosis were undetected (isosignal) (fig 1 and table 2). Of the 56 cavernomas, 33 (59\%) were supratentorial, 22 $(39 \%)$ infratentorial and one $(2 \%)$ spinal (table 3). Their maximum diameters in the MRI images ranged from 1 to $4 \mathrm{~cm}$.

The six patients with multiple cavernomas (fig 2) comprised three females with three lesions each, two females with two lesions each and one male with two lesions. A woman with multiple cavernomas showed aqueductal stenosis due to a lesion in the anterior

Table 3 Locations of 56 CNS cavernomas in 47 patients

\begin{tabular}{lcc}
\hline Location & Number & $\%$ \\
\hline Supratentorial: & 33 & 59 \\
Frontal & 4 & $7 \cdot 25$ \\
Temporal & 13 & 23 \\
Parietal & 8 & $14 \cdot 5$ \\
Occipital & 2 & $3 \cdot 5$ \\
Thalamus & 4 & $7 \cdot 25$ \\
Infratentorial: & 22 & 39 \\
Cerebral peduncles & 4 & $7 \cdot 25$ \\
Pons & 10 & 18 \\
Medulla & 2 & $3 \cdot 5$ \\
Cerebellum and connections & 6 & $10 \cdot 25$ \\
Spinal cord $(D 4):$ & 1 & 2 \\
\hline
\end{tabular}

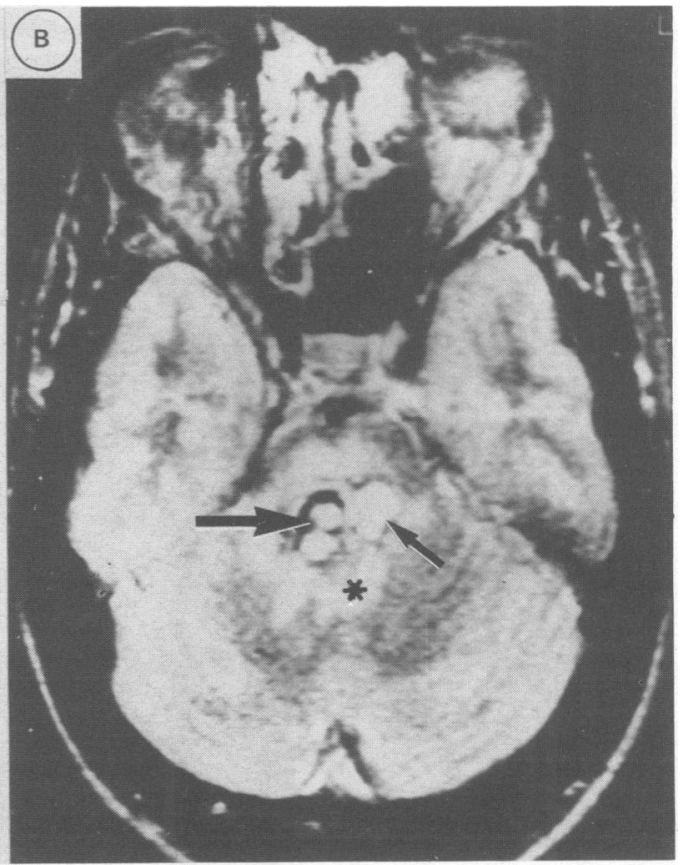

Figure 1 A) Sagittal $M R$ image (T2, TE1) of a medullar cavernoma: peripheral low signal ring (haemosiderin) and central heterogeneous signal. B) Axial MRI (T2,TE2) of a pontine cavernoma with two haemorrhagic nodules within the lesion (arrow) and one outside

(arrowhead). Note the because of oedema $\left.{ }^{\star}\right)$. 
Figure 2 Coronal MRI (T2, TE1) of a patient with multiple cavernomas left cerebellar lesion with homogeneous high signal because of recent

haemorrhage and a second right temporal one (a third right parietal lesion not included in this image).

Figure 3 A) Axial CT image showing triventricular hydrocephalus without evidence of

parenquimatous lesion. B) Coronal MRI ( $T 2$, $T E 1)$ of the same woman reveals a superior vermian cavernoma causing aqueductal stenosis and a right cerebellar cavernoma.
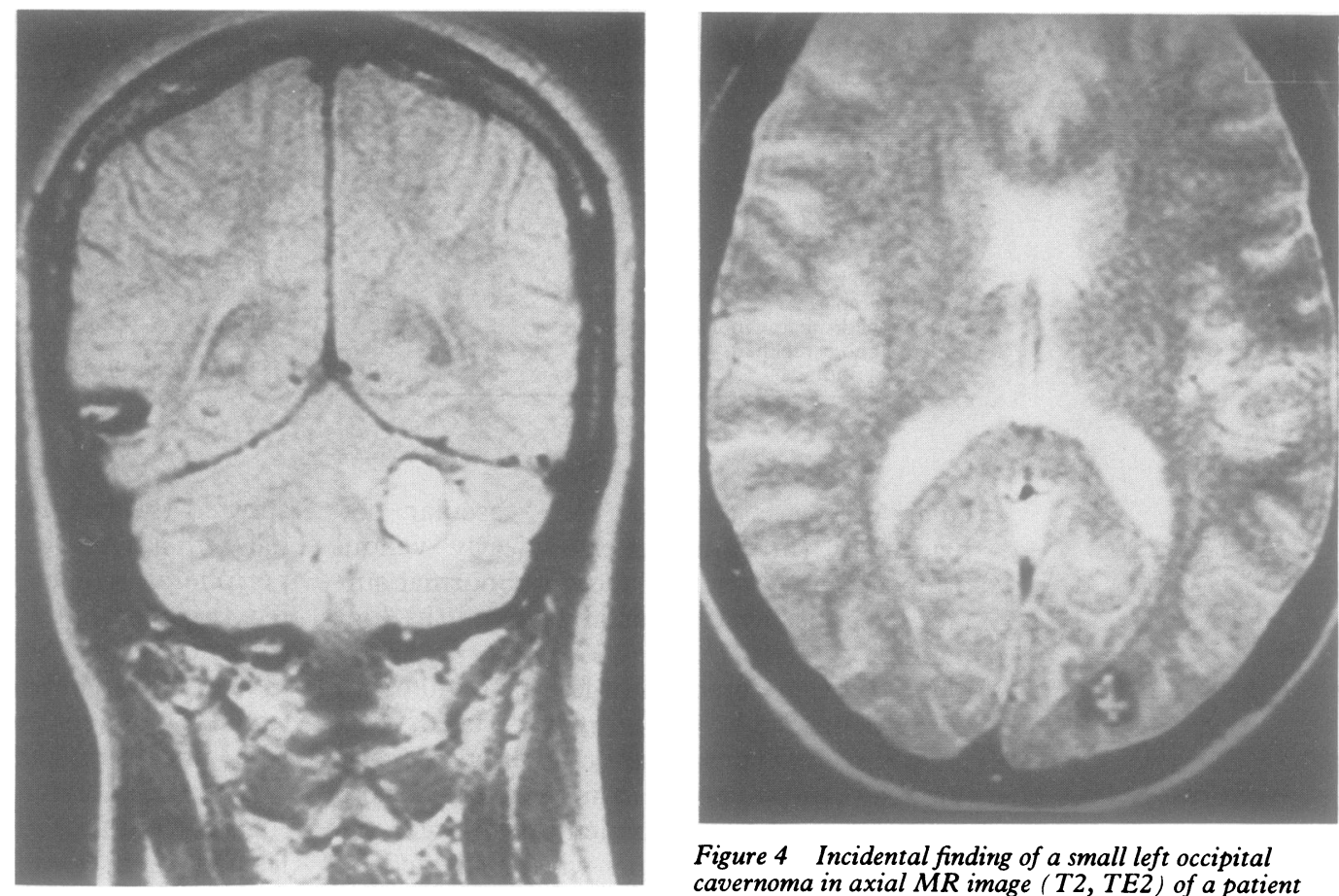

Figure 4 Incidental finding of a small left occipital cavernoma in axial MR image (T2, TE2) of a patient with Parkinson's disease.
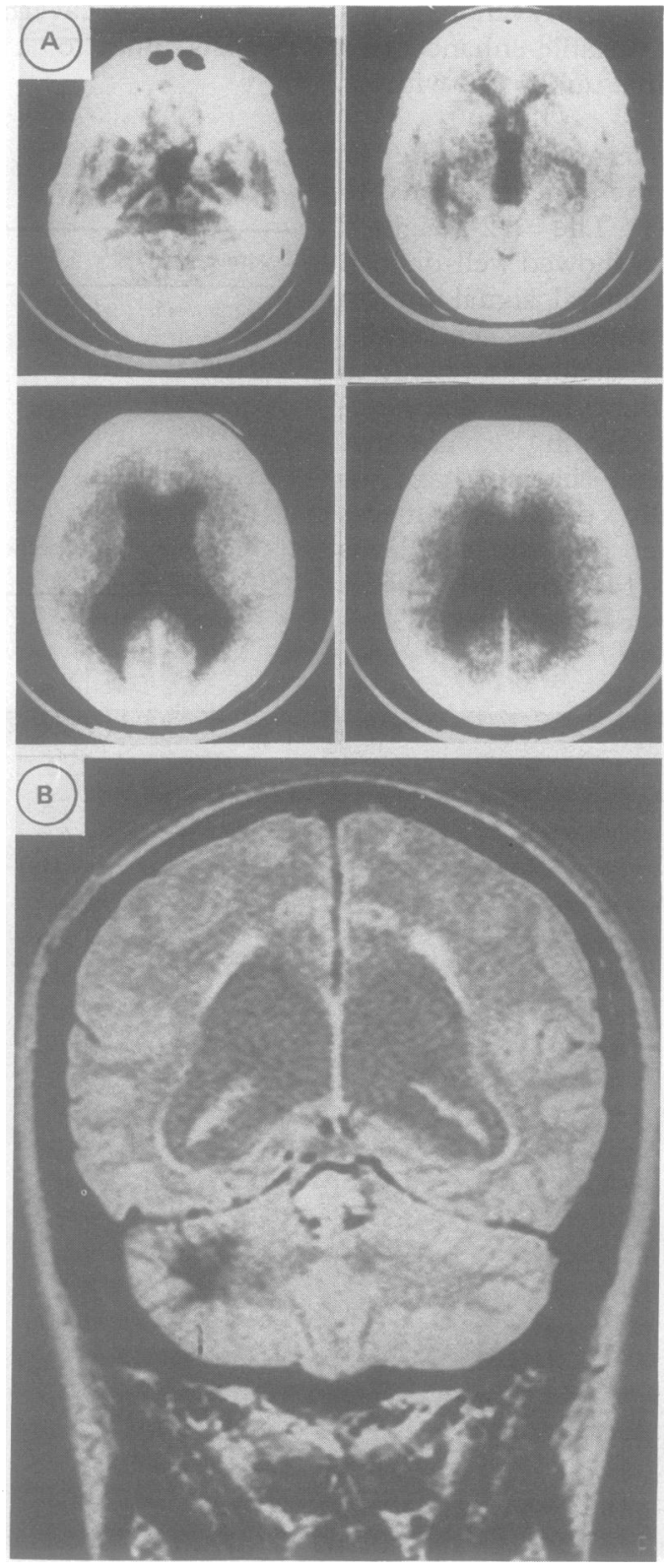

cerebellar vermis and triventricular hydrocephalus (fig 3). A case of cavernoma of the corpus callosum also showed parasagittal meningioma. Two patients had associated cavernous-venous malformations, and the male with two cavernomas showed abnormal surface venous drainage due to partial agenesis of the superior longitudinal sinus. In five patients cavernoma was an incidental finding (fig 4).

\section{Discussion}

A striking feature of these findings is the age difference between the male and female groups. Eleven of the 21 males $(52.4 \%)$ were diagnosed as cavernoma cases before the age of 30 years, compared with only three of 26 females $(11.5 \%)$. It seems possible that as yet unknown hormonal factors may play some role in the biology of cavernomas.

The incidence of cavernoma has been reported to be greater among males than females, ${ }^{33}$ greater among females than males, ${ }^{34}$ and the same for both sexes. ${ }^{16}$ In this study there were more female than male patients (26 against 21 ) and more females had multiple lesions than males $(19 \cdot 2 \%$ versus $4 \cdot 8 \%)$.

As in other studies ${ }^{81618}$ the incidence of familial cavernomas in this series was low, the two patients who were sisters, making up just $4.3 \%$ of the group, but we did not systematically investigate the families of the patients. Family screening increases the number of diagnoses of familial cavernoma; ${ }^{35}$ Rigamonti et $a l^{22}$ found that $54 \%$ of their patients were familial cases, and that multiple cavernoma was much commoner in this group.

The location of the cavernomas (table 3 ) correlated well with clinical manifestations. Eighteen of the 33 patients with supratentorial lesions had epilepsy, while 14 of 22 infratentorial lesions had ictal, progressive or fluctuating brainstem syndromes. Tentative clini- 
cal diagnoses in some infratentorial cases included multiple system atrophy, multiple sclerosis and Miller-Fisher syndrome. There was a high incidence of asymtomatic lesions, $21 \cdot 4 \%$ ( 12 lesions) if the clinically unobtrusive lesions of the multiple cavernoma cases are included. The commonest site of supratentorial cavernomas was temporal lobe (13 lesions), and that of infratentorial cavernomas the pons ( 10 lesions).

In all the 24 cases in which it was performed, angiography failed to reveal cavernoma. The observed angiographic alterations (vascular displacement, early drainage) are not specific for cavernomas, since they may also be observed in cases of telangiectasis, venous angioma, thrombosed arteriovenous malformations, ischaemic lesions, glioma and inflammatory states. ${ }^{36-40}$ In no case did we observe peripheral capillary blush, but then this shows up better after a second injection series ${ }^{41}$ that was not performed in this study. Nor did we detect any case of so-called hypervascular dural cavernoma of the middle cranial fossa. ${ }^{23242641}$ The abnormal surface drainage vein of the man with two cavernomas is attributed to the partial lack of the superior sagittal sinus.

CT detected 40 cavernomas in the 45 patients with whom it was performed. The radiological characteristics of these lesions were similar to those described previously::28 $2930424335(87.5 \%)$ had high or heterogeneous density, were poorly delinated and were only slightly enhanced by intravenous contrast injection, while five $(12.5 \%)$ were hypodense. Nine $(22.5 \%)$ exhibited calcification. No totally calcified cavernoma, or "cerebral stone" ${ }^{44} 4$ was observed. Triple-dose contrast injection was not used because MRI was available; reports ${ }^{31}$ that it improves cavernoma detection by CT have not been confirmed by other authors. ${ }^{32}$

In the 45 patients on whom both CT and MRI were employed, MRI detected 54 cavernomas, including 14 that CT had failed to detect (most of them small lesions located deep in the temporal fossa or in the infratentorial compartment). No cavernoma detected by CT went undetected by MRI. CT is more specific for detecting calcium, which in MRI images may be confused with blood flow, haemosiderin or other alterations, but calcified areas were not invisible in MRI images as has been reported. ${ }^{6}$ Since the shape and location of the lesions and the signal characteristics listed in table 2 made the MRI of the cavernomas much more distinctive than their CT images, we consider MRI to be both more sensitive and more specific than CT for cavernoma diagnosis. MRI is also useful for monitoring the evolution, since signals vary according to the stage after a haemorrhage and with the variations in oedema around the lesion. Mass effect, diffuse high signals and other possible features of cavernomas or their images may hinder differential diagnosis of entities such as metastases and haematomas; in such cases diagnosis should be based on clinical and neuroimaging features. ${ }^{272846}$

The spinal (D4) cavernoma, which like the other 17 surgically removed tumours was confirmed histopathologically, was not detected by computer-assisted myelography.

In two radiated brainstem cavernomas, $M R I$ showed transient high peripheral T2 signals due to oedema, which disappeared in two weeks, so that the pre- and post-radiated images were similar. Some authors ${ }^{847}$ consider surgical treatment to be mandatory in casesincluding brainstem cases ${ }^{8}$ - which exhibit recent haemorrhage or mass effect, since their removal is facilitated by the circumscribing peripheral gliosis.

We conclude that cavernomas with clinical consequences seem to occur at an earlier age in males than in females. Multiple lesions are more common among females. The main clinical manifestations are epilepsy and brainstem syndromes, though many lesions are asymptomatic. Angiography fails to detect this kind of CNS vascular malformation, and a significant number go undetected by CT. The most sensitive and specific technique for detection, characterisation and monitoring of CNS cavernomas is MRI.

1 Stein BM, Mohr JP. Vascular malformations of the brain. $N$ Eng J Med 1988;319:368-9.

2 Kramer RA, Wing SD. Computed tomography of angiographically occult cerebral vascular malformations. Radiology 1977;123:649-52.

3 Bitoh S, Hasegawa H, Fujiwara M, Sakurai M. Angiographically occult vascular malformations causing intracranial hemorrhage. Surg Neurol 1982;17:35-42.

4 Chin D, Harper C. Angiographically occult cerebral vascular malformations with abnormal computed tomocular malformations with abnormal
graphy. Surg Neurol 1983;20:138-42.

5 Lemme-Plaghos L, Kucharzick W, Brant-Zawadzki M, et al. MRI of angiographically occult vascular malformations. AJR 1986;146:1223-8.

6 New PJ, Ojemann RG, Davis KR, et al. MR and CT of occult vascular malformations of the brain. AJR 1986;147:985-93.

7 el-Gohary EG, Tomita T, Gutierrez FA, McLone DG. Angiographically occult vascular malformations in childhood. Neurosurgery 1987;20:759-66.

8 Yasargil MG. Venous, Cavernous and Occult Angiomas. In: Yasargil MG, ed. Microneurosurgery (Vol 3B). Stuttgart: Georg Thieme Verlag, 1988:405-38.

9 Rubinstein LJ. Tumours of central nervous system. Washington DC, Armed Forces Institute of Pathology, 1972.

10 Russell DS, Rubinstein LJ. Pathology of tumours of the nervous system. 4th ed. London: Edward Arnold, 1977.

11 Otten P, Pizzolato GP, Rilliet B, Berney J. A propos de 131 cas d'angiomas caverneux (cavernomes) du SNC repérés par l'analyse rétrospective de 24.535 autopsies. Neurochirurgie 1989;35:82-3.

12 Berry RG, Alpers BJ, White JC. The site, structure and frequency of intracranial aneurisms, angiomas and arteriovenous abnormalities. Res Publ Assoc Res Nerv Ment Dis 1966;41:40-72.

13 McCormick WF, Nofzinger JD. "Cryptic" vascular malformations of the central nervous system. J Neurosurg 1966; 24:865-75.

14 Sarwar M, McCormick WF. Intracerebral venous angioma. Arch Neurol 1978;35:323-5.

15 Martin NA, Stein BM, Wilson CB. Arteriovenous malformations of the posterior fossa. In: Wilson CB, Stein BM, mations of the posterior fossa. In: Wilson CB, Stein BM, eds. Intracranial arterioveneous malform

16 Voigt K, Yasargil MG. Cerebral cavernous hemangiomas or cavernomas. Incidence, pathology, localization, diagnosis, clinical features and treatment. Review of the literature and report of an unusual case. Neurochirurgia 1976;19: 59-68.

17 Clark JV. Familial occurrence of cavernous angiomata of the brain. J Neurol Neurosurg Psychiatry 1970;33:871-6.

18 Bicknell JM, Carlow TJ, Kornfeld M, Stovring J, Turner P. Familial cavernous angiomas. Arch Neurol 1978;35:746-9.

19 Hayman LA, Evans RA, Ferrell RE, Fahr LM, Ostrow P, Riccardi VM. Familial cavernous angiomas. Natural history and genetic study over a five-year period. $\mathrm{Am} \mathrm{J} \mathrm{Med}$ Genet 1982;11:147-60.

20 Rigamonti D, Hadley MN, Drayer BP, et al. Cerebral cavernous malformations. Incidence and familial cavernous malformations. Incidence 1 .

21 Chadduck WM, Binet EF, Farrell FW Jr, Araoz CA, Reding DL. Intraventricular cavernous hemangioma. Report of three cases and review of the literature. Neurosurgery three cases and 
22 Vaquero J, Carrillo R, Cabezudo JU, Leunda G, Villoria F, Bravo $G$. Cavernous angiomas of the pineal region. Report of two cases. J Neurosurg 1980;53:833-5.

23 Mori K, Handa H, Gi H, Mori K. Cavernomas in the middle fossa. Surg Neurol 1980;14:21-31.

24 Ishikawa M, Handa $\mathrm{H}$, Moritake $\mathrm{K}$, et al. Computed tomography of cerebral cavernous hemangiomas. $J$ Comput Assist Tomogr 1980;4:587-91.

25 Voci A, Panzarasa G, Formaggio G, Arrigoni M, Geuna E. Les cavernomes de localisation rare: 4 observations personnelles. Neurochirurgie 1989;35:99-101.

26 Rao VRK, Pillai SM, Shenoy KT, et al. Hypervascular cavernous angioma at angiography. Neuroradiology 1979; cavernous

27 Steiger HJ, Markwalder RV, Reulen HJ. Y a-t-il une relation entre manifestation clinique et l'image pathologique des cavernomes cérébraux? Neurochirurgie 1989; 35:84-8.

28 Sigal R, Halimi P, Doyon D, Blas C, Chan KY. Imagerie des cavernomes de l'encéphale. Tomodensitométrie et imagerie par Résonance Magnétique. Neurochirurgie

29 Savoiardo M, Strada L, Passerini A. Intracranial cavernous hemangiomas: neuroradiologic review of 36 operated cases. Am J Neuroradiol 1983;4:945-50.

30 Simard JM, Garcia-Bengoechea F, Bollinger WE, Mickle P, Quisling RG. Cavernous angioma: A review of 126 Quisling RG. Cavernous angioma: A review of 126
collected and 12 new clinical cases. Neurosurgery 1986 ; collected and

31 Kurata A, Irikura K, Kitahara I, et al. The usefulness of prolonged high dose delayed contrast computed tomography for the diagnosis of intracranial angiographically occult vascular malformations (Abstract). No Shinkei Geka 1985;13:867-73.

32 Hayman LA, Fox AJ, Evans RA. Effectiveness of contrast regimes in CT detection of vascular malformations of the brain. AJNR 1981;2:421-5.

33 Giombini S, Morello G. Cavernous angiomas of the brain. Account of fourteen personal cases and review of the literature. Acta Neurochirurgica 1978;40:61-82.

34 Yamasaki $\mathrm{T}$, Handa $\mathrm{H}$, Yamashita J, et al. Intracranial and orbital cavernous angioma. A review of 30 cases. $J$ Neurosurg 1986;64:197-208.
35 Allard JC, Hochberg FH, Franklin PD, Carter AP Magnetic resonance imaging in a family with hereditary cerebral arteriovenous malformations. Arch Neurol 1989, 46:184-7.

36 Roberson GH, Kase CS, Wolpow ER. Telangiectases and cavernous angiomas of the brainstem. "Cryptic" vascula malformations. Report of a case. Neuroradiology 1974 8:83-9.

37 Heinz ER. Pathology involving the supratentorial veins and dural sinuses. In: Newton TH, Potts DG, eds. Radiology of the skull and brain. St Louis: Mosby, 1974:1878.

38 Michels LG, Bentson JR, Winter J. Computed tomography of cerebral venous angiomas. J Comput Assist Tomogr 1977;1:149-54.

39 Saito Y, Kobayashi N. Cerebral venous angiomas. Clinical evaluation and possible etiology. Radiology 1981;139: 87-94.

40 Leblanc R, Ethier R. The computerized tomographic appearance of angiographically occult malformations of the brain. Canad J Neurol Sci 1981;8:7-13.

41 Huang YP, Ohta T, Okudera T, Robbins A. Anatomic variations in the dural venous sinuses. In: Kapp JP, Schmidek $\mathrm{HH}$, eds. The cerebral venous system and its disorders. Orlando: Grune and Stratton, 1984:109-67.

42 Steiger HJ, Tew JM Jr. Hemorrhage and epilepsy in cryptic cerebrovascular malformations. Arch Neurol 1984;41: 722-4.

43 Servo A, Porras M, Raininko R. Diagnosis of cavernous haemangiomas by computed tomography and angiohraphy. Acta Neurochir 1984;71:133-8.

44 Di Tullio MV Jr, Stern WE. Hemangioma calcificans. Case report of an intraparenchymatous calcified vascular hematoma with epileptogenic potential. J Neurosurg 1979; 50:110-4.

45 Kasantikul V, Wirt TC, Allen VA, Netzky MG. Identification of a brain stone as calcified hemangioma: case report. $J$ Neurosurg 1980;52:862-6.

46 Sze G, Krol G, Olsen W, et al. Hemorrhagic neoplasms: MR mimics of occult vascular malformations. AJR 1987; 149:1223-30.

47 Vaquero J, Salazar J, Martinez R, Martinez P, Bravo G. Cavernomas of the central nervous system. Acta Neurochir 1987;85:29-33. 